\title{
Review
}

\section{Fas ligand, death gene}

\author{
MJ Pinkoski*,1 and DR Green*,1 \\ 1 Division of Cellular Immunology, La Jolla Institute for Allergy and \\ Immunology, 10355 Science Center Drive, San Diego, California, CA 92121, \\ USA \\ * Corresponding authors: MJ Pinkoski and DR Green, Division of Cellular \\ Immunology, La Jolla Institute for Allergy and Immunology, 10355 Science \\ Center Drive, San Diego, California, CA 92121, USA. Tel: (858) 558-3500; \\ Fax: (858) 558-3525; E-mail: michael@liai.org; dgreen5240@aol.com
}

Received 2.8.99; revised 1.10.99; accepted 5.10 .99

Edited by L Fesus

\begin{abstract}
The concept of death genes goes back to the early days of programmed cell death, when a researcher's model system was required to be dependent on transcription of the dying cell in order to qualify as apoptosis. In 1987 Andrew Wyllie, ${ }^{1}$ one of the pioneers of cell death research, outlined four 'cardinal elements' of apoptosis: one of which was a requirement for macromolecular synthesis. In the following years the complexity of the apoptotic process has become evident and while it is now clear that apoptosis does not have to rely on gene expression, the idea of death genes remains. Induction of an apoptotic cascade via activation of caspases, selective release of mitochondrial proteins and further activation of caspases, can be stimulated by engagement of the Fas surface molecule via membrane bound or soluble forms of Fas ligand (FasL). The FasL gene, which is often transcriptionally inactive, becomes activated in many forms of transcription/ translation dependent apoptosis. Here we will discuss FasL as a candidate death gene.
\end{abstract}

Keywords: apoptosis; CD95 ligand; immune homeostasis and privilege; gene regulation

\section{Introduction}

Much of the early characterization of apoptosis was performed in thymocytes treated with either antibody to engage the $\mathrm{T}$ cell receptor (TCR) or by treatment with glucocorticoid. $^{2-6}$ In these situations, thymocyte death is dependent on RNA and protein synthesis because apoptosis was not observed when the cells were treated in the presence of actinomycin D, an inhibitor of RNA synthesis, or in the presence of cycloheximide, an inhibitor of protein synthesis.

However, it was later shown that not all apoptosis requires new RNA or protein synthesis by the condemned cell. In 1990, Martin et al. ${ }^{7}$ reported that the human promyelocytic cell line, HL-60, treated with the calcium ionophore, A23187, or the microtubule disruptors, colchicine and vinblastine was not rescued from apoptosis by the presence of cycloheximide or actinomycin $\mathrm{D}$. Rather than protecting against cell death, both of these agents induced significant death in HL-60 cells, thus demonstrating that not all apoptosis was dependent on transcription and translation. In fact, this provided an inkling of the complexity of programmed cell death that would soon become evident. However, the fact remained that in some cases, transcription is required for apoptosis to occur and it is now pretty much agreed that the requirement for novel RNA and protein synthesis in apoptosis is dependent on the cell type and the apoptotic stimulus. In those cases when apoptosis is dependent on transcription, the genes that must be transcribed have been termed 'death genes'. Socalled death genes are those that are not transcriptionally active unless there is some sort of death stimulus. Without proper activation of the appropriate death gene(s), the ultimate goal of cell death cannot be achieved in some settings. Here, we will discuss one set of scenarios where this is the case.

\section{Fas ligand as a $\mathrm{T}$ cell death gene}

The cytotoxic protein, FasL, that binds the surface molecule Fas was identified in 1993 as a type II membrane protein of $40 \mathrm{kDa}$ that is expressed on lymphoid cells as well as in tissues involved in peripheral deletion and sites of immune privilege. ${ }^{8}$ FasL has also been isolated in a soluble form from patients with large granular lymphocytic (LGL) leukemia and natural killer (NK) cell lymphoma. ${ }^{9}$ FasL is a member of the tumor necrosis factor (TNF) family of proteins and induces apoptosis in cells bearing Fas (CD95/APO-1) on the plasma membrane by setting in motion a sequential activation of what is becoming a well-defined process.

FasL engages surface Fas, a member of the TNF receptor family. ${ }^{10}$ Trimerization of Fas results in recruitment of the death inducing signaling complex, DISC, which includes the accessory molecules FADD and pro-caspase8 as principal components (see ${ }^{11,12}$ ). Activation of caspase8 , in turn, activates the execution phase of the death program, which appears to follow one of two routes: via direct cleavage and activation of caspase- 3 or by indirectly causing the release of mitochondrial cytochrome c. Upon release, cytochrome $c$ is recruited to the apoptosome with APAF-1 and pro-caspase 9 which leads to nuclear and cellular degradation. Although more complex than outlined here, the two pathways can be described according to the involvement of proteins recruited to the DISC and potential inhibition by bcl-2 family members. (A more comprehensive review of the caspase family of proteases and the initiation and execution phases of apoptosis, which are beyond the scope of this article, can be found in references ${ }^{13-15}$ ).

\section{AICD proceeds via FasL upregulation}

One of the most compelling arguments implicating FasL as a death gene is its involvement in activation induced cell death 
(AICD). After clonal expansion of lymphocytes in response to antigen, the immune system is faced with the task of clearing vast numbers of activated lymphocytes. Failure to do so would result in T cells running amok, posing the potential risk of selfdestructive activity. Apoptosis was shown to be the mode of AICD responsible for peripheral deletion of activated lymphocytes, that is, ones that have been primed and are immunologically reactive ${ }^{16}$ (see Figure 1).

Shi et al. ${ }^{17}$ reported that AICD of thymocytes and T cell hybridomas was inhibited by cyclosporin $A$ and the same year Ucker et al. ${ }^{18}$ demonstrated that AICD required de novo RNA and protein synthesis, suggesting the involvement of death genes. The death gene involved in AICD was later identified as FasL by four separate research groups early in 1995 who showed that FasL expressed in response to TCR stimulation mediated its apoptotic effect through interaction with Fas displayed on the surface of activated $\mathrm{T}$ cells. ${ }^{19-22}$ Although TNF can also induce apoptosis in activated T cells, ${ }^{23}$ FasL-mediated AICD is believed to be a primary mechanism responsible for limiting the number of effector $\mathrm{T}$ cells following immune responsive expansion.

\section{Lessons from the Ipr colony, or, there's gld in them thar mice}

Perhaps the most useful and informative tools in the study of Fas and FasL are the Ipr and gld mutant mice. Each of these

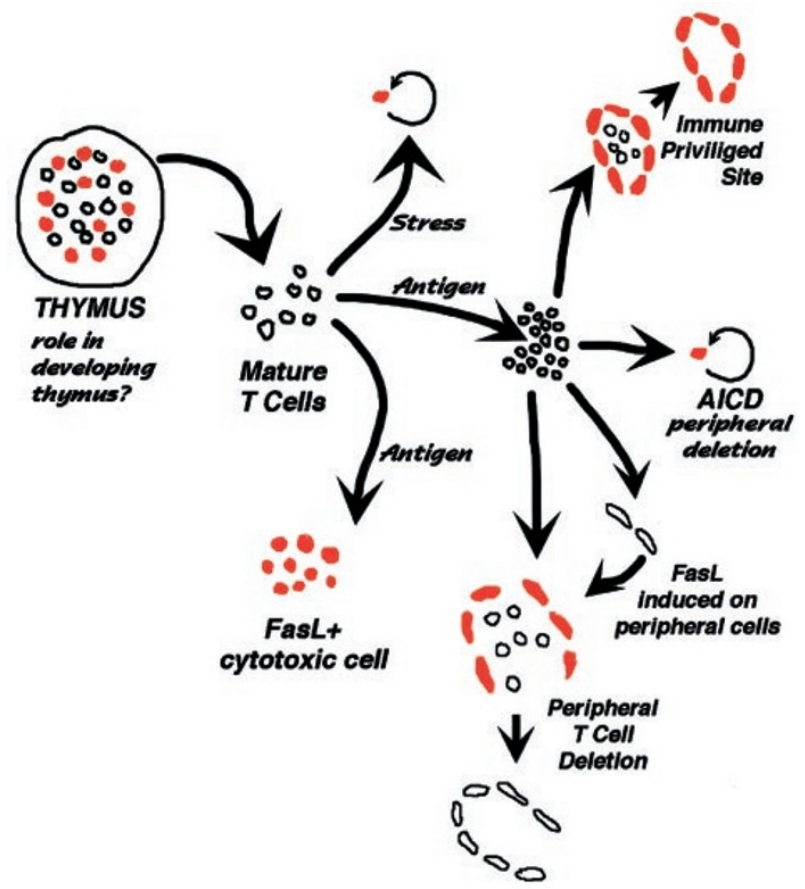

Figure 1 Schematic outline of cells expressing FasL. Starting with a possible role in negative selection of thymocytes, FasL is upregulated and displayed on the surface of activated peripheral T cells, during AICD and in non-lymphoid tissues at sites of immune privilege and peripheral deletion. The filled red cells represent those expressing FasL mice arose from spontaneous mutations that manifested as severe lymphoproliferative disorders (see Cohen and Eisenberg $\left.{ }^{24}\right)$. In 1992, the mutation responsible for the Ipr (lymphoproliferation) phenotype was identified in the Fas gene. ${ }^{25}$ Similarly, a mutation in the human Fas gene has been described and, as in the Ipr mouse, is associated with lymphoproliferative and autoimmune disorders. ${ }^{26}$ In 1994 , Takahashi et al. identified the gld defect as a point mutation in the FasL gene that results in FasL mRNA being expressed but the protein rendered nonfunctional. ${ }^{27}$ Both of $I p r$ and gld mice have massive accumulation of activated T cells, perhaps due to an inability to clear peripheral lymphocytes as a result of inoperative Fas-FasL mediated apoptosis in these cells.

\section{Stress induced FasL expression in T cells}

Recently another physiological system in which transcription-dependent apoptosis occurs via the upregulation of FasL has received considerable attention. Stress, in the form of heat shock, genotoxic insult or radiation, has been demonstrated to occur via apoptotic death that can be associated with activation of the FasL gene and be at least partially dependent on the presence of functional FasL protein. Killing by DNA damaging agents, long the mainstay of antitumor chemotherapy, has been shown to involve Fas/FasL for efficient killing in some cases. ${ }^{28-30}$ When CEM and Jurkat $T$ cells were treated with the chemotherapeutic agent, doxorubicin, these cells underwent apoptosis which was associated with activation of the FasL gene. ${ }^{28}$ As with AICD, the apoptosis observed in these cells is characterized by the increased expression of Fas-L mRNA, which is required for death. Fulda et al. ${ }^{31}$ demonstrated this phenomenon with doxorubicin, cis-platin and VP16, all of which have DNA damage as a primary mode of action. Kasibhatla et al. $^{30}$ outlined a mechanism for FasL expression induced by DNA damage in activated lymphocytes which is discussed below. The involvement of the Fas-FasL trigger to induce apoptosis in these systems is supported by the observation that $\gamma$-radiation and heat shock treatment of splenic cells from Ipr mice did not produce as profound an apoptotic response as from wildtype lymphocytes. ${ }^{29}$

\section{FasL in negative selection: does too, does not, does too}

AICD in the thymus manifests as negative selection, the process by which self-reactive thymocytes are deleted before leaving the thymus. In the original papers on autonomous killing of activated T cells through Fas-L, ${ }^{19-22}$ the observation was made that this phenomenon provided a possible explanation for death of thymocytes during negative selection, a proposal that was made previously based on the differential expression of Fas during $T$ cell ontogeny. ${ }^{32}$ However, studies with Ipr mutant, FADD knockout (FADD - /-) and FADD dominant negative transgenic mice suggest that this may not be the case.

Ipr mice treated with the superantigen SEB (Staphylococcal enterotoxin B) did not show any significant impairment of thymic deletion compared to SEB treated wild-type mice. ${ }^{33}$ 
Similar results were reported by Adachi et al. ${ }^{34}$ who generated a Ipr/lpr (Fas-/-) mouse by directed targeting of the Fas gene. Although peripheral deletion was reduced in these mice, thymic deletion appeared to be normal. Recently, it was shown that Fas-FasL may play a role in negative selection during early thymic development in gestation. It was proposed that the apoptotic signaling mechanism responsible for Fas-mediated negative selection in utero may be overridden by a TCR signal in postnatal mice. ${ }^{35}$

In recent studies it was proposed that Fas/FasL regulated negative selection is dependent on the dose of antigen. SEB treated $I p r$ mice did not show any defects in negative selection unless the mice received at least $100 \mu \mathrm{g} \mathrm{SEB} .^{36}$ In studies using the OVA-specific TCR (DO10) transgenic mouse crossed with the Ipr mouse, negative selection was significantly impaired in DO10/pr/lpr mice treated with $150 \mu \mathrm{g}$ OVA peptide. ${ }^{37}$ DO10 Fas+/+ mice treated with similar doses of OVA peptide showed expansion of OVA-TCR-bearing clones, but had no difficulties deleting these cells after removal of the antigen. ${ }^{37}$

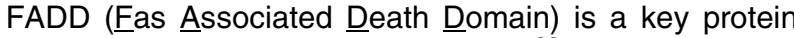
in Fas-mediated signaling in apoptosis. ${ }^{38}$ Since it acts in physical conjunction with Fas, it provides one of the most apical regulators of Fas killing as demonstrated through the use of dominant negative mutants of FADD, which inhibit FasL induced apoptosis. Ablation of the FADD gene in knockout mice resulted in severe problems during embryogenesis, but negative selection was not perturbed. ${ }^{39}$

A similar result was observed in the transgenic mouse expressing a dominant negative variant of FADD (ddFADD) under the control of the $\mathrm{T}$ cell specific $\mathrm{p56} 6^{\text {lck }}$ promoter. ${ }^{40}$ As in the FADD-/- mice, there was no appreciable impairment of negative selection in the ddFADD transgenic, suggesting that apoptosis of these cells is likely not driven through a Fas mediated process. Thus, since the dominant negative FADD abrogates signaling through Fas, then by extension FasL cannot be acting through this pathway to induce death during negative selection. It has recently been reported that Fas can signal through an alternative, FADD-independent, pathway using the Fasassociated adaptor molecule, DAXX, which results in activation of Jun terminal kinase and NF- $\kappa \mathrm{B} .{ }^{41,42}$ There is a possibility that Fas/Fas-L may still play a role in negative selection, but the mechanism and outcome of such an activity have yet to be characterized.

Interestingly, cycloheximide induced apoptosis of T cells, similar to that described earlier, ${ }^{7,43}$ was found to be dependent on FADD. ${ }^{44}$ A similar observation was made in U937 leukemia cells undergoing apoptosis induced by the anticancer drugs VP16 and CDDP. ${ }^{45}$ Although U937 cells died in a FADD-dependent manner, apoptosis in this system appeared to be independent of FasL.

\section{Genetic regulation of Fas ligand NFAT}

We have seen that FasL is upregulated in physiological situations, but what are the cellular players that drive the transcription of FasL? To date a number of transcriptional activators of the FasL gene have been identified. A summary of factors that bind the FasL proximal promoter is shown in Figure 2. One of the first regulatory regions examined in the FasL gene was mapped from -487 to $-271 \mathrm{bp}$, relative to the transcription start site at +1 . This region contains two binding sites for NFAT (Nuclear Factor in Activated I cells), a transcription factor activated by engagement of the TCR. ${ }^{46}$ DNA footprint analysis showed that there were two sites bound by NFAT in this region corresponding to the consensus NFAT sequence. ${ }^{47}$

\section{$\mathbf{N F}-\kappa \mathbf{B}$}

In addition to NFAT, the FasL contains a responsive element for NF- $\kappa \mathrm{B}$, a heterodimer of NF- $\kappa \mathrm{B} 1$ (p50) and RelA (p65). In T cells, NF- $\kappa \mathrm{B}$ is activated by phosphorylation-induced inactivation of its inhibitor, $\mathrm{I}_{\kappa} \mathrm{B} .{ }^{48}$ Upon release from $\mathrm{I}_{\kappa} \mathrm{B}, \mathrm{NF}-\kappa \mathrm{B}$ then translocates to the nucleus. NF- $\kappa$ B-dependent upregulation of FasL has been demonstrated in apoptosis of etoposide and teniposide treated Jurkat. ${ }^{30}$ Recently a thymine-dependent colon carcinoma cell line that dies in a Fas-mediated manner $^{49}$ was shown to upregulate FasL in a NF- $\kappa \mathrm{B}$ dependent manner during thymine withdrawal induced death (Harwood et al, 1999, submitted). This suggests that NF- $\kappa \mathrm{B}$ may represent a general regulator of FasL transcription. In support of this possibility, recently, FasL mediated apoptosis observed during AICD has been recently demonstrated to be mediated via NF- $\kappa$ B. ${ }^{50}$

\section{Egr}

In 1996 Norian et $a l,{ }^{51}$ described a response element in the FasL promoter at position -214 to -207 , denoted RE3, and demonstrated that this site is necessary, in conjunction with the NFAT responsive element, for the coordinated expression of FasL in activated $T$ cells. Mittlestadt and Ashwell identified an overlapping site $(-220$ to $-205 \mathrm{bp})$ as the response element for the transcription factor Egr (Early Growth Response). ${ }^{52}$ Two members of the Egr family, Egr-2 and Egr-3, bind this site and contribute to the expression of FasL in T cells at two stages of ontogeny. Expression of Egr-2 is highest in double negative, $\mathrm{CD}^{+} \mathrm{CD}^{-} \mathrm{CD}^{-}$, thymocytes and Egr-3 is highly expressed in activated peripheral $\mathrm{T}$ lymphocytes. Since both of these proteins recognize the same element in the FasL promoter, it is likely that they provide specificity for the genetic regulation of FasL. It has not yet been established whether the TCR-activated transcription factor

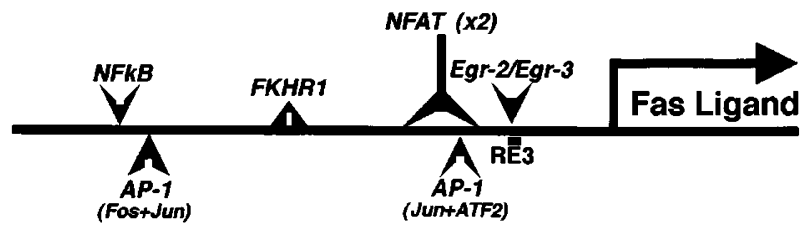

Figure 2 The proximal promoter of the FasL gene showing the respective regulatory elements and transcriptional regulators that have been shown to be involved in FasL expression 
acting through RE3 is Egr-2, Egr-3 or perhaps another Egr family member. ${ }^{52,53}$

\section{Stress can kill}

One mechanism by which stress kills is through the activation of the p38 Jun terminal kinase (JNK; also known as SAPK for $\underline{\text { Stress }}$ Activated Protein Kinase). JNK, which is activated by a phosphorylation driven signaling pathway, phosphorylates c-Jun which then translocates to the nucleus and with its binding partner c-Fos forms AP-1 and binds its regulatory element in the FasL promoter. Rincón ${ }^{54}$ recently demonstrated that JNK is activated in response to the initiation of negative selection of thymocytes and that JNK activity is mediated through the MAP kinase signaling pathway. Using a mouse transgenic for a dominant negative JNK, these researchers found that thymocyte development was severely compromised, notably, the resistance of DP thymocytes that were refractory to TCR-induced apoptosis which resulted in the accumulation of immature thymocytes. These observations were complemented by observations in the JNK1 knockout mouse in which there was also a severe reduction in the responsiveness of DP thymocytes to TCRinduced apoptosis during negative selection. ${ }^{55}$ JNK2 appears to play a role later in the thymocyte's life given that studies with the JNK2 knockout mouse, in which negative selection was not adversely affected, showed that JNK2 is required for activation and apoptosis of mature T cells. ${ }^{56}$ Although JNK1 and JNK2 appear to act in T cells at different stages, it is clear that they both play an important role in apoptosis of $T$ cells. The mechanism by which each impacts the genetic regulation of FasL and ultimately $\mathrm{T}$ cell death has yet to be determined.

Also contained in the cluster of response elements in the -400 to $-200 \mathrm{bp}$ region of the FasL promoter is a site implicated in the responsiveness to cellular stress. Using deletion analyses Faris et al, identified a region as a MEKK1 responsive element that they showed was bound by an AP-1 heterodimer of c-Jun and ATF-2 (Activating Transcription Factor-2), in a footprint spanning -338 to $-316 \mathrm{bp}$ of the FasL promoter. ${ }^{57}$ This element is required for optimal responsiveness to such cellular stress as UVand $\gamma$-radiation.

Distal to the TCR-responsive regulatory elements of the FasL promoter is a region that contains at least two sites that are important for the upregulation of FasL in response to stress and cytotoxic insult. Cytotoxic stress and DNA damage induce apoptosis mediated through the activation of transcription factors $\mathrm{AP}-1^{58}$ and $\mathrm{NF}-\kappa \mathrm{B}$ through the activation of the upstream regulatory pathway via sequential phosphorylation events by MAP kinases, SAPKs and JNKs. Kasibhatla et al, ${ }^{30}$ have identified a region in the FasL promoter $(-1.2$ to $-0.9 \mathrm{~kb})$ that is required for upregulation of FasL transcription by $N F-\kappa B$ and $A P-1$ by deletion analysis of the FasL promoter with a reporter gene assay. An AP-1 consensus sequence (TTAGTCAG) was identified within this region that is required for $A P-1$ dependent activation of the FasL promoter. ${ }^{30}$

This provides evidence for a model to explain the induction of a death gene, FasL, as has been suggested by observations with such inducers as genotoxic insult by chemotherapeutic agents, ${ }^{57,59}$ growth factor withdrawal in neuronal cell death, ${ }^{60}$ and ionizing, UV- and $\gamma$-radiation. ${ }^{30}$

\section{c-myc}

The c-myc protein is a transcription factor that was initially implicated in the induction of apoptosis in fibroblasts under serum starvation, ${ }^{61}$ and has since been shown to contribute to cell death in AICD of T cell hybridomas. ${ }^{62}$ Bissonette et al, later showed that myc, in conjunction with its heterodimer partner, max, is required for apoptosis in activated T cells ${ }^{63}$ and in 1997, Hueber et $a l^{64}$ demonstrated that induction of apoptosis by $c-m y c$ requires the presence of functional Fas and FasL. Since AICD in T cells is mediated via upregulation of FasL, it is likely that $c-m y c$ participates in this effect ( $T$ Brunner, personal communication).

It has been postulated that c-myc exerts an effect on the transcriptional activity of the FasL gene by a direct interaction in the proximal FasL promoter. It has recently been reported that TGF $\beta 1$ abrogates the c-myc-mediated induction of FasL mRNA synthesis and subsequent apoptosis, which provides a means to downregulate AICD, possibly to allow antigen dependent clonal expansion during an immune response. ${ }^{65}$

\section{Forkhead FKHRL1 getting in on the Akt?}

A novel response element has been mapped in the FasL promoter that is bound by a Forkhead transcription factor, FKHRL1. ${ }^{66}$ FKHRL1 is a substrate of the kinase Akt (or PKB, protein kinase $B),{ }^{67,68}$ which has been implicated in apoptotic signaling by the discovery that it phosphorylates caspase- 96 and BAD, a pro-apoptotic member of the bcl-2 family member. ${ }^{70}$ Akt has been shown to translocate to the nucleus upon activation ${ }^{71,72}$ in the presence of essential growth factors, without which apoptosis would occur. Phosphorylation of FKHRL1 renders it inactive as a transcription factor and in its dephosphorylated form, FKHRL1 can contribute to the upregulation of FasL expression through a responsive element in the region of -743 to $-648 \mathrm{bp}$ upstream of the initiation codon. ${ }^{66}$ These findings are consistent with an earlier report that Akt suppresses FasL-dependent apoptosis. $^{73}$ The mechanisms controlling Akt kinase and FKHRL1 involvement in FasL expression remain to be elucidated.

\section{Fas ligand as an intercellular death signal}

Killing by cytotoxic T cells occurs by one of two defined modi operandi. ${ }^{74-76}$ The first method elucidated involves the vectoral secretion of the cytolytic granules from the CTL into the microenvironment between the CTL and its target. Apoptotic proteases, the primary one being granzyme B, along with perforin induce rapid apoptosis in the target and release of the CTL to kill again. Granzyme B enters the target cell autonomously but requires perforin to activate the target that has been primed for rapid apoptotic destruction by the presence of granzyme B. ${ }^{77,78} \mathrm{~A}$ hallmark feature of granulemediated killing by CTL is the requirement for $\mathrm{Ca}^{2+}$, which is necessary for the proper polymerization and/or activation of perforin. 
A second mechanism of killing by CTL was proposed based on the observation that in some conditions CTL could kill their targets in a $\mathrm{Ca}^{2+}$-independent manner ${ }^{79-81}$ and it was later demonstrated that peritoneal exudate lymphocytes (PEL) do not contain detectable levels of perforin protein ${ }^{81}$ or mRNA. ${ }^{82}$ These preliminary observations, although originally met with skepticism, were supported by the identification of the antigen recognized by two independently generated cytotoxic antisera. $\alpha$-APO$1^{83}$ and $\alpha-\mathrm{Fas}^{84}$ both of which recognize the surface protein that has been renamed CD95 (Fas; APO-1). Binding of Fas by $\alpha$-Fas $(\alpha$-APO- 1$)$ mimicks the events when Fas is bound by its cognate ligand, which was identified 4 years later. ${ }^{8}$ FasL and $\alpha$-Fas both engage surface Fas and initiate the apoptotic pathway as described above.

Rouvier et $a l,{ }^{85}$ used target cells from gld and Ipr mice, as well as targets transfected with Fas, to demonstrate that there is in fact an alternative mode of CTL killing, one which is mediated through surface receptor interactions involving Fas. CTL killing by FasL/Fas interaction accounts for the earlier observations of $\mathrm{Ca}^{2+}$ - and antigenindependent apoptosis of targets. It is now believed that killing by FasL on the surface of CTL and NK cells is the preferred weapon of choice for clearing activated CTL and NK cells following antigen-driven expansion, while granule mediated killing appears to be preferred to kill virus infected and tumor cells as the primary targets.

Bossi and Griffiths ${ }^{86}$ have thrown additional light onto the CTL/FasL story in a report in which they show that FasL is contained in the cytolytic granules of CTL. Although constitutively expressed, FasL is maintained in an intracellular store until activation of the peripheral CTL, after which FasL is transported from its storage compartment to the cell surface, thus creating a fully armed and operational cytotoxic cell.

\section{Fas ligand as a death gene in non-lymphoid cells}

\section{Immune privilege}

Immune privilege is a system used to delineate forbidden zones for lymphocytes in order to protect certain organs, such as the eye and testes, from encountering anything more than the slightest of inflammation that would accompany a local immune response in these tissues. ${ }^{87,88}$ If an immune response is provoked in the anterior chamber of the eye, there is a dramatic reduction in vision (see Ferguson and Griffith ${ }^{88}$ ). The expression of FasL by non-lymphoid cells in the eye causes the death of any infiltrating Fas ${ }^{+}$lymphocytes. The FasL cells in this case act very much like CTL that kill via FasL/Fas, however the purpose is to remove any interloping lymphocytes before an immune response can be mounted in these 'protected' tissues (see Figure 1).

Griffith et $a l^{89}$ demonstrated that immune privilege can be gained by the expression of FasL by cells at these sites. For example, the presence of FasL on the surface of cells in the anterior chamber of the eye can rapidly clear virus infected cells placed into this region without the necessity for infiltrating lymphocytes. ${ }^{90}$ A similar infection in the eye of gld mice resulted in lymphocyte invasion of the anterior chamber and inflammation at that site. Also contributing to the maintenance of immune privilege is $\operatorname{TGF} \beta$, which was found in the microenvironment of transplanted $\mathrm{FasL}^{+}$colon carcinoma cells, CT26-CD95L, into the intraocular space. ${ }^{91}$ TGF $\beta$ was shown to downregulate the expression of Fas on the infiltrating neutrophils, which serves to moderate a potential inflammatory response.

Bellgrau et al, ${ }^{92}$ employed a strategy based on the FasL model of immune privilege to prevent graft rejection. These researchers demonstrated that testicular Sertoli cells expressing functional FasL were able to survive transplantation under the kidney capsule. Sertoli cells from gld mice were not able to survive transplantation in this manner, suggesting that survival of FasL-bearing grafts was due to the graft 'defending' itself against immune attack by the host. This issue is far from settled, however, since FasL ${ }^{+}$ islet $\beta$ cells transplanted under the kidney capsule of allogeneic recipient mice suffered from major granulocytic infiltration. ${ }^{93}$ The presence of FasL on the grafted $\beta$ cells did not confer any resistance to rejection compared with non-FasL bearing grafts.

\section{Peripheral deletion}

Although the primary means of removing activated peripheral $T$ cells is through AICD, a second approach has been elucidated in which FasL is expressed in non-lymphoid tissues. In a system resembling immune privilege, inducible FasL expression has been demonstrated in cells found at common sites of lymphocyte infiltration and clearance, notably hepatocytes and epithelial cells of the small intestine. ${ }^{94}$ This discovery has not laid to rest the argument over how and why lymphocytes home to places such as the gut where they apparently induce a death gene by which to direct their own demise, but it provides an elegant biological system to complement peripheral deletion by lymphoid tissue and does so in a site that can accommodate major lymphocytic infiltration.

\section{Neurons join the fray}

Neurons provide an example where FasL induction of apoptosis in non-lymphoid tissue does not involve lymphocytes as the inducer or target of apoptotic stimuli. A recent report outlined the activation of the FasL gene in PC12 cells and primary neuron cultures during apoptosis induced by withdrawal of nerve growth factor or $\mathrm{KCl}$, respectively. ${ }^{60}$ Apoptosis of both the PC12 cells and cerebellar granule neurons was accompanied by increased levels of FasL, which was required for death to occur. Further supporting the role of FasL in the death of neurons are the experiments showing that death is abrogated by Fas-Fc, an inhibitor of FasL, and in neurons from gld mice.

Martin-Villalba et al, recently reported similar findings in neuronal cells undergoing apoptosis after ischemia. ${ }^{95}$ Inhibition of c-Jun phosphorylation, in this case with FK506, abrogated upregulation of FasL transcription and subsequent cell death. Ischemia in Ipr mice did not result in the same level of neuronal apoptosis as in wild- 
type mice, thus providing more evidence for the involvement of FasL as a death gene in neuronal apoptosis. Upregulation of FasL by neuronal cells may also serve as a means to protect neurons from infiltrating cells in a manner similar to immune privilege. $^{96}$

\section{Tumor counterattack}

Another example of FasL gene expression in non-lymphoid tissue is the presence of FasL protein on the surface of many tumors. Initially observed in melanomas ${ }^{97}$ and hepatocellular carcinomas, ${ }^{98}$ FasL has now been observed on a number of tumor types (reviewed in ${ }^{99}$ ). The tumors' use of FasL to kill off infiltrating Fas-bearing lymphocytes, akin to immune privilege, has been termed tumor counterattack. It is not known if the expression of FasL by tumor cells is an early event that provides a competitive advantage for a nascent neoplasm, or if it is a defense mechanism acquired or selected later in tumor progression.

The presence of surface FasL is not sufficient to guarantee survival of a tumor. Transplantation or injection of FasL-bearing tumors into mice has also been demonstrated to evoke an inflammatory response. Shimizu et al, ${ }^{100}$ injected Neuro-2a neuroblastoma cells transfected with FasL CDNA and observed significant infiltration of neutrophils at the site of injection. An inflammatory response was not observed when recipient mice were treated with neutralizing anti-FasL antibody or when Neuro2a-FasL cells were injected into $/ p r$ mice, suggesting that FasL may contribute to the inflammatory response including neutrophil recruitment and activation.

Seino et al, ${ }^{101}$ demonstrated that FasL-bearing tumor cells were efficiently eradicated by syngeneic recipient mice if the graft cells did not also express Fas. Deletion of the transplanted cells was mediated by infiltrating $\mathrm{CD}^{+} \mathrm{CTL}$ and NK cells. Similar observations were reported by Arai et $a{ }^{102}$ who demonstrated that the $\mathrm{Fas}^{-}$colon carcinoma cell line CT26-CD95L, when placed in syngeneic hosts, elicited a strong inflammatory response and was cleared rapidly by inflammatory cells. Presence of FasL on Fas-bearing renal carcinoma, Renca, cells did not protect these cells from apoptotic death when transplanted into syngeneic hosts, however, no inflammatory response was observed. Chen et al, ${ }^{91}$ have since demonstrated that the inflammatory response mediated by FasL is dependent on the microenvironment at the site of introduction of a graft. CT26 expressing FasL (CT26-CD95L), when injected subcutaneously, elicited a strong inflammatory response and the graft was cleared by infiltrating neutrophils. The inflammatory response was suppressed in the presence of $\operatorname{TGF} \beta$, which inhibited neutrophil activation. Similarly, when injected intraocularly, CT26-CD95L cells did not elicit an inflammatory response due to the presence of TGF $\beta$ at the site of injection.

\section{Conclusions}

Although Wyllie's fourth cardinal element of apoptosis only emphasized the requirement for protein synthesis, ${ }^{1}$ the necessity for new gene expression was listed as a necessity in some experimental systems. Our understanding of apoptosis and the need for macromolecular biosynthesis at that time was characterized mainly by seminal studies which were based on, but not limited to, death of thymocytes and mature $\mathrm{T}$ cells in the context of cytokine withdrawal and hormone induced cell death. ${ }^{2-4}$ Over the past 12 years we have seen the unravelling of the complexity of apoptosis, not only with the biochemical pathways leading to death, but in the vast number of physiological systems that rely on apoptosis for homeostasis.

Although a number of these systems do not require novel RNA or protein synthesis, significant cell death occurs that is absolutely dependent on transcription of death genes. In light of this and considering the involvement of FasL in AICD during immune homeostasis and maintenance of immune privilege, we feel that FasL qualifies as a bona fide death gene. What we learn from FasL and other death genes may lead us to better understanding of such problems as lymphoproliferative and autoimmune disorders and possibly to develop novel strategies to avoid rejection of transplants and to combat tumors.

\section{Acknowledgements}

MJ Pinkoski is a Post-Doctoral Fellow of the Medical Research Council of Canada. We thank Drs T Lin and N Waterhouse for critical reading of the manuscript and helpful comments. This is LIAI manuscript number 316.

\section{References}

1. Wyllie $\mathrm{AH}$ (1987) Apoptosis: cell death in tissue regulation. J. Pathol. 153:313316

2. Wyllie AH (1980) Glucocorticoid-induced thymocyte apoptosis is associated with endogenous endonuclease activation. Nature 28: 555-556

3. Wyllie AH and Morris RG (1982) Hormone-induced cell death. Purification ad properties of thymocytes undergoing apoptosis after glucocorticoid treatment. Am. J. Pathol. 109: 78-87

4. Wyllie AH, Morris RG, Smith AL and Dunlop D (1984) Chromatin cleavage in apoptosis: association with condensed chromatin morphology and dependence on macromolecular synthesis. J. Pathol. 142: 67-77

5. Cohen JJ and Duke RC (1984) Glucocorticoid activation of a calciumdependent endonuclease in thymocyte nuclei leads to cell death. J. Immunol. 132: $38-42$

6. Ucker DS (1987) Cytotoxic T lymphocytes and glucocorticoids activate an endogenous suicide process in target cells. Nature 327: 62-64

7. Martin SJ, Lennon SV, Bonham AM and Cotter TG (1990) Induction of apoptosis (programmed cell death) in human leukemic HL-60 cells by inhibition of RNA or protein synthesis. J. Immunol. 145: 1859-1867

8. Suda T, Takahashi T, Golstein P and Nagata S (1993) Molecular cloning and expression of the Fas ligand, a novel member of the tumor necrosis factor family. Cell 75: 1169-1178

9. Tanaka M, Suda T, Haze K, Nakamura N, Sato K, Kimura F, MotoyoshiK, Mizuki M, Tagawa S, Ohga S, Hatake K, Drummond AH, Nagata S (1996) Fas ligand in human serum. Nature Med. 2: 317-322

10. Itoh N, Yonehara S, Ishii A, Yonehara M, Mizushima S, Sameshima M, Hase A, Seto Y, Nagata S (1991) The polypeptide encoded by the cDNA for human cell surface antigen Fas can mediate apoptosis. Cell 66: 233-243

11. Nagata S (1997) Apoptosis by death factor. Cell 88: $355-365$

12. Green DR (1998) Apoptotic pathways: the roads to ruin. Cell 94: 695-698

13. Ashkenazi A and Dixit VM (1998) Death receptors: signaling and modulation. Science 281: $1305-1308$

14. Thornberry NA and Lazebnik Y (1998) Caspases: enemies within. Science 281: $1312-1316$ 
15. Wolf BB and Green DR (1999) Suicidal tendencies: apoptotic cell death by caspase family proteinases. J. Biol. Chem. 274: 20049-20052

16. Shi YF, Szalay MG, Paskar L, Sahai BM, Boyer M, Singh B, Green DR (1990) Activation-induced cell death in T cell hybridomas is due to apoptosis. Morphologic aspects and DNA fragmentation. J. Immunol. 144: $3326-3333$

17. Shi YF, Sahai BM and Green DR (1989) Cyclosporin A inhibits activationinduced cell death in T-cell hybridomas and thymocytes. Nature 339: 625-626

18. Ucker DS, Ashwell JD and Nickas G (1989) Activation-driven T cell death. I. Requirements for de novo transcription and translation and association with genome fragmentation. J. Immunol. 143: 3461 - 3469

19. Dhein J, WalczakH, Baumler C, Debatin KM and KrammerPH(1995) Autocrine T-cell suicide mediated by APO-1/(Fas/CD95). Nature 373: 438-441

20. Brunner T, Mogil RJ, LaFace D, Yoo NJ, Mahboubi A, Echeverri F, Martin SJ, Force WR, Lynch DH, Ware CF, Green DR (1995) Cell-autonomous Fas (CD95)/Fas-ligand interaction mediates activation-induced apoptosis in T-cell hybridomas. Nature 373: 441-444

21. Ju ST, Panka DJ, Cui H, Ettinger R, el-Khatib M, Sherr DH, Stanger BZ, Marshak-Rothstein A (1995) Fas(CD95)/FasL interactions required for programmed cell death after T-cell activation. Nature 373: 444-448

22. Alderson MR, Tough TW, Davis-Smith T, Braddy S, Falk B, Schooley KA, Goodwin RG, Smith CA, Ramsdell F, Lynch DH (1995) Fas ligand mediates activation-induced cell death in human T lymphocytes. J. Exp. Med. 181: $71-$ 77

23. Zheng L, Fisher G, Miller RE, Peschon J, Lynch DH and Lenardo MJ (1995) Induction of apoptosis in mature T cells by tumour necrosis factor. Nature 377: $348-351$

24. Cohen PLand Eisenberg RA (1991) Lprand gld: single gene models of systemic autoimmunity and lymphoproliferative disease. Annu. Rev. Immunol. 9: $243-$ 269

25. Watanabe-Fukunaga R, Brannan Cl, Copeland NG, Jenkins NA and Nagata S (1992) Lymphoproliferation disorder in mice explained by defects in Fas antigen that mediates apoptosis. Nature 356: $314-317$

26. Rieux-Laucat F, Le Deist F, Hivroz C, Roberts IA, Debatin KM, Fischer A, de Villartay JP (1995) Mutations in Fas associated with human lymphoproliferative syndrome and autoimmunity. Science 268: 1347-1349

27. Takahashi T, Tanaka M, Brannan Cl, Jenkins NA, Copeland NG, Suda T, Nagata S (1994) Generalized lymphoproliferative disease in mice, caused by a point mutation in the Fas ligand. Cell 76: 969-976

28. Friesen C, Herr I, Krammer PH and Debatin KM (1996) Involvement of the CD95 (APO-1/FAS) receptor/ligand system in drug-induced apoptosis in leukemia cells. Nature Med. 2: 574-577

29. Reap EA, Roof K, Maynor K, Borrero M, Booker J and Cohen PL (1997) Radiation and stress-induced apoptosis: a role for Fas/Fas ligand interactions. Proc. Natl. Acad. Sci. USA 94: 5750-5755

30. Kasibhatla S, Brunner T, Genestier L, Echeverri F, Mahboubi A and Green DR (1998) DNA damaging agents induce expression of Fas ligand and subsequent apoptosis in T lymphocytes via the activation of NF-kappa B and AP-1. Mol. Cell 1: $543-551$

31. Fulda S, Scaffidi C, Pietsch T, Krammer PH, Peter ME and Debatin KM (1998) Activation of the CD95 (APO-1/Fas) pathway in drug- and gamma- irradiationinduced apoptosis of brain tumor cells. Cell Death Differ. 5: 884-893

32. Debatin KM, Suss D and Krammer PH (1994) Differential expression of APO-1 on human thymocytes: implications for negative selection? Eur. J. Immunol. 24: $753-758$

33. Mogil RJ, Radvanyi L, Gonzalez-Quintial R, Miller R, Mills G, Theofilopoulos AN, Green DR (1995) Fas (CD95) participates in peripheral T cell deletion and associated apoptosis in vivo. Int. Immunol. 7: 1451-1458

34. Adachi M, Suematsu S, Suda T, Watanabe D, Fukuyama H, Ogasawara J Tanaka T, Yoshida N, Nagata S (1996) Enhanced and accelerated lymphoproliferation in Fas-null mice. Proc. Natl. Acad. Sci. USA 93: 2131 2136

35. Fleck M, Zhou T, Tatsuta T, Yang P, Wang Z and Mountz JD (1998) Fas/Fas ligand signaling during gestational T cell development. J. Immunol. 160:37663775

36. Kishimoto H, Surh CD and Sprent J (1998) A role for Fas in negative selection of thymocytes in vivo. J. Exp. Med. 187: 1427-1438

37. Kurasawa K, Hashimoto Y and Iwamoto I (1999) Fas Modulates both Positive and Negative Selection of Thymocytes. Cell. Immunol. 194: 127-135
38. Chinnaiyan AM, O'Rourke K, Tewari Mand Dixit VM(1995) FADD, a novel death domain-containing protein, interacts with the death domain of Fas and initiates apoptosis. Cell 81:505-512

39. Yeh WC, Pompa JL, McCurrach ME, Shu HB, Elia AJ, Shahinian A, Ng M, Wakeham A, Khoo W, Mitchell K, El-Deiry WS, Lowe SW, Goeddel DV, Mak TW (1998) FADD: essential for embryo development and signaling from some, but not all, inducers of apoptosis. Science 279: 1954-1958

40. Walsh CM, Wen BG, Chinnaiyan AM, O'Rourke K, Dixit VM and Hedrick SM (1998) A role for FADD in T cell activation and development. Immunity 8: 439449

41. Chang HY, Nishitoh $H$, Yang $X$, Ichijo $H$ and Baltimore $D$ (1998) Activation of apoptosis signal-regulating kinase 1 (ASK1) by the adapter protein Daxx. Science 281: 1860-1863

42. Chang HY, Yang X and Baltimore D (1999) Dissecting Fas signaling with an altered-specificity death-domain mutant: requirement of FADD binding for apoptosis but not Jun N-terminal kinase activation. Proc. Natl. Acad. Sci. USA 96: $1252-1256$

43. Martin SJ (1993) Protein or RNA synthesis inhibition induces apoptosis of mature human CD4+ T cell blasts. Immunol. Lett. 35: 125-134

44. Tang D, Lahti JM, Grenet J and Kidd VJ (1999) Cycloheximide-induced T-cell death is mediated by a Fas-associated death domain-dependent mechanism. J. Biol. Chem. 274: 7245-7252

45. Micheau O, Solary E, Hammann A and Dimanche-Boitrel MT (1999) Fas ligandindependent, FADD-mediated activation of the Fas death pathway by anticancer drugs. J. Biol. Chem. 274: 7987-7992

46. Rao A, Luo C and Hogan PG (1997) Transcription factors of the NFAT family: regulation and function. Annu. Rev. Immunol. 15: 707-747

47. Latinis KM, Norian LA, Eliason SL and Koretzky GA (1997) Two NFAT transcription factor binding sites participate in the regulation of CD95 (Fas) ligand expression in activated human T cells. J. Biol. Chem. 272:31427-31434

48. Baldwin Jr AS (1996) The NF-kappa B and I kappa B proteins: new discoveries and insights. Annu. Rev. Immunol. 14: 649-683

49. Houghton JA, Harwood FG and Tillman DM (1997) Thymineless death in colon carcinoma cells is mediated via fas signaling. Proc. Natl. Acad. Sci. USA 94: $8144-8149$

50. Kasibhatla S, Genestier L and Green DR (1999) Regulation of fas-ligand expression during activation-induced cell death in T lymphocytes via nuclear factor kappaB. J. Biol, Chem. 274: 987-992

51. Norian LA, Latinis KM and Koretzky GA (1998) A newly identified response element in the CD95 ligand promoter contributes to optimal inducibility in activated T lymphocytes. J. Immunol. 161: 1078-1082

52. Mittelstadt PR and Ashwell JD (1998) Cyclosporin A-sensitive transcription factor Egr-3 regulates Fas ligand expression. Mol. Cell. Biol. 18: 3744-3751

53. Mittelstadt PR and Ashwell JD (1999) Role of Egr-2 in up-regulation of Fas ligand in normal T cells and aberrant double-negative Ipr and gld T cells. J. Biol. Chem. 274: 3222-3227

54. Rincón M, Whitmarsh A, Yang DD, Weiss L, Derijard B, Jayaraj P, Davis RJ, Flavell RA (1998) The JNK pathway regulates the In vivo deletion of immature CD4(+)CD8(+) thymocytes. J. Exp. Med. 188: 1817-1830

55 Dong C, Yang DD, Wysk M, Whitmarsh AJ, Davis RJ and Flavell RA (1998) Defective T cell differentiation in the absence of Jnk1. Science 282: 2092-2095

56. Sabapathy K, Hu Y, Kallunki T, Schreiber M, David JP, Jochum W, Wagner EF, Karin M (1999) JNK2 is required for efficient T-cell activation and apoptosis but not for normal lymphocyte development. Curr. Biol. 9: 116-125

57. Faris M, Latinis KM, Kempiak SJ, Koretzky GA and Nel A (1998) Stress-induced Fas ligand expression in T cells is mediated through a MEK kinase 1-regulated response element in the Fas ligand promoter. Mol. Cell. Biol. 18: 5414-5424

58. Karin M, Liu Zand Zandi E (1997) AP-1 function and regulation. Curr. Opin. Cell. Biol. 9: 240-246

59. Faris M, Kokot N, Latinis K, Kasibhatla S, Green DR, Koretzky GA, Nel A (1998) The c-Jun N-terminal kinase cascade plays a role in stress-induced apoptosis in Jurkat cells by up-regulating Fas ligand expression. J. Immunol. 160: 134-144

60. Le-Niculescu H, Bonfoco E, Kasuya Y, Claret FX, Green DR and Karin M (1999) Withdrawal of survival factors results in activation of the JNK pathway in neuronal cells leading to Fas ligand induction and cell death. Mol. Cell. Biol. 19: $751-763$

61. Evan GI, Wyllie AH, Gilbert CS, Littlewood TD, Land H, Brooks M, Waters CM, Penn LZ, Hancock DC (1992) Induction of apoptosis in fibroblasts by c-myc protein. Cell 69: 119-128 
62. Shi Y, Glynn JM, Guilbert LJ, Cotter TG, Bissonnette RP and Green DR (1992) Role for c-myc in activation-induced apoptotic cell death in $\mathrm{T}$ cell hybridomas. Science 257: 212-214

63. Bissonnette RP, McGahon A, Mahboubi A and Green DR (1994) Functional Myc-Max heterodimer is required for activation-induced apoptosis in $\mathrm{T}$ cell hyrbidomas. J. Exp. Med. 180: 2413-2418

64. Hueber AO, Zornig M, Lyon D, Suda T, Nagata S and Evan GI (1997) Requirement for the CD95 receptor-ligand pathway in c-Myc-induced apoptosis. Science 278: 1305-1309

65. Genestier L, Kasibhatla S, Brunner T and Green DR (1999) Transforming growth factor beta1 inhibits Fas ligand expression and subsequent activationinduced cell death in T cells via downregulation of c-Myc. J. Exp. Med. 189: 231-239

66. Brunet A, Bonni A, Zigmond MJ, Lin MZ, Juo P, Hu LS, Anderson MJ, Arden KC, Blenis J, Greenberg ME (1999) Akt promotes cell survival by phosphorylating and inhibiting a Forkhead transcription factor. Cell 96: $857-868$

67. Hillion J, Le Coniat M, Jonveaux P, Berger R and Bernard OA (1997) AF6q21, a novel partner of the MLL gene in $t(6 ; 11)(q 21 ; q 23)$, defines a forkhead transcriptional factor subfamily. Blood 90: 3714-3719

68. Anderson MJ, Viars CS, Czekay S, Cavenee WK and Arden KC (1998) Cloning and characterization of three human forkhead genes that comprise an FKHRlike gene subfamily. Genomics 47: 187-199

69. Cardone MH, Roy N, Stennicke HR, Salvesen GS, Franke TF, Stanbridge E, Frisch S, Reed JC (1998) Regulation of cell death protease caspase-9 by phosphorylation. Science 282: 1318-1321

70. Wang HG, Pathan N, Ethell IM, Krajewski S, Yamaguchi Y, Shibasaki F, McKeon F, Bobo T, Franke TF, Reed JC (1999) Ca2+-induced apoptosis through calcineurin dephosphorylation of BAD. Science 284: 339-343

71. Andjelkovic M, Alessi DR, Meier R, Fernandez A, Lamb NJ, Frech M, Cron P, Cohen P, Lucocq JM, Hemmings BA (1997) Role of translocation in the activation and function of protein kinase B. J. Biol. Chem. 272: 31515-31524

72. Meier R, Alessi DR, Cron P, Andjelkovic Mand Hemmings BA (1997) Mitogenic activation, phosphorylation, and nuclear translocation of protein kinase Bbeta. J. Biol. Chem. 272: 30491-30497

73. Rohn JL, Hueber AO, McCarthy NJ, Lyon D, Navarro P, Burgering BM, Evan GI (1998) The opposing roles of the Akt and c-Myc signalling pathways in survival from CD95-mediated apoptosis. Oncogene 17: 2811-2818

74. Darmon AJ, Pinkoski MJ and Bleackley RC (1999) Granule-mediated cytotoxicity. Results Probl. Cell Differ. 23: 103-125

75. Berke G (1995) PELs and the perforin and granzyme independent mechanism of CTL-mediated lysis. Immunol. Rev. 146: 21-31

76. Berke G (1995) The CTL's kiss of death. Cell 81: $9-12$

77. Pinkoski MJ, Hobman M, Heibein JA, Tomaselli K, Li F, Seth P, Froelich CJ, Bleackley RC (1998) Entry and trafficking of granzyme B in target cells during granzyme B-perforin-mediated apoptosis. Blood 92: 1044-1054

78. Shi L, Mai S, Israels S, Browne K, Trapani JA and Greenberg AH (1997) Granzyme B (GraB) autonomously crosses the cell membrane and perforin initiates apoptosis and GraB nuclear localization. J. Exp. Med. 185: 855-866

79. Berke $G$ and Rosen D (1988) Highly lytic in vivo primed cytolytic T lymphocytes devoid of lytic granules and BLT-esterase activity acquire these constituents in the presence of $\mathrm{T}$ cell growth factors upon blast transformation in vitro. J. Immunol. 141: 1429-1436

80. Schick B and Berke G (1990) The lysis of cytotoxic T lymphocytes and their blasts by cytotoxic T lymphocytes. Immunology 71: 428-433

81. Berke G, Rosen D and Ronen D (1993) Mechanism of lymphocyte-mediated cytolysis: functional cytolytic $\mathrm{T}$ cells lacking perforin and granzymes. Immunology 78: 105-112

82. Helgason CD, Prendergast JA, Berke G and Bleackley RC (1992) Peritoneal exudate lymphocyte and mixed lymphocyte culture hybridomas are cytolytic in the absence of cytotoxic cell proteinases and perforin. Eur. J. Immunol. 22 $3187-3190$
83. Trauth BC, Klas C, Peters AM, Matzku S, Moller P, Falk W, Debatin KM, Krammer PH (1989) Monoclonal antibody-mediated tumor regression by induction of apoptosis. Science 245: $301-305$

84. Yonehara S, Ishii A and Yonehara M (1989) A cell-killing monoclonal antibody (anti-Fas) to a cell surface antigen co-downregulated with the receptor of tumor necrosis factor. J. Exp. Med. 169: 1747-1756

85. Rouvier E, Luciani MF and Golstein P (1993) Fas involvement in $\mathrm{Ca}(2+)-$ independent T cell-mediated cytotoxicity. J. Exp. Med. 177: 195-200

86. Bossi G and Griffiths GM (1999) Degranulation plays an essential part in regulating cell surface expression of Fas ligand in T cells and natural killer cells. Nature Med. 5: 90-96

87. Green DR and Ware CF (1997) Fas-ligand: privilege and peril. Proc. Natl. Acad. Sci. USA 94: 5986-5990

88. Ferguson TA and Griffith TS (1997) A vision of cell death: insights into immune privilege. Immunol. Rev. 156: 167-184

89. Griffith TS, Brunner T, Fletcher SM, Green DR and Ferguson TA (1995) Fas ligand-induced apoptosis as a mechanism of immune privilege. Science 270 : 1189-1192

90. Griffith TS, Yu X, Herndon JM, Green DR and Ferguson TA (1996) CD95induced apoptosis of lymphocytes in an immune privileged site induces immunological tolerance. Immunity 5: 7-16

91. Chen JJ, Sun Y and Nabel GJ (1998) Regulation of the proinflammatory effects of Fas ligand (CD95L). Science 282: 1714-1717

92. Bellgrau D, Gold D, Selawry H, Moore J, Franzusoff A and Duke RC (1995) A role for CD95 ligand in preventing graft rejection. Nature 377: 630-632

93. Allison J, Georgiou HM, Strasser A and Vaux DL (1997) Transgenic expression of CD95 ligand on islet beta cells induces a granulocytic infiltration but does not confer immune privilege upon islet allografts. Proc. Natl. Acad. Sci. USA 94: 3943-3947

94. Bonfoco E, Stuart PM, Brunner T, Lin T, Griffith TS, Gao Y, Nakajima H, Henkart PA, Ferguson TA, Green DR (1998) Inducible nonlymphoid expression of Fas ligand is responsible for superantigen-induced peripheral deletion of $\mathrm{T}$ cells. Immunity 9: 711-720

95. Martin-Villalba A, Herr I, Jeremias I, Hahne M, Brandt R, Vogel J, Schenkel J, Herdegen T, Debatin KM (1999) CD95 ligand (Fas-L/APO-1L) and tumor necrosis factor-related apoptosis-inducing ligand mediate ischemia-induced apoptosis in neurons. J. Neurosci. 19: 3809-3817

96. Sabelko-Downes KA, Cross AH and Russell JH (1999) Dual role for Fas ligand in the initiation of and recovery from experimental allergic encephalomyelitis. J. Exp. Med. 189: 1195-1205

97. Hahne M, Rimoldi D, Schroter M, Romero P, Schreier M, French LE, Schneider P, Bornand T, Fontana A, Lienard D, Cerottini J, Tschopp J (1996) Melanoma cell expression of Fas(Apo-1/CD95) ligand: implications for tumor immune escape. Science 274: 1363-1366

98. Strand S, Hofmann WJ, Hug H, Muller M, Otto G, Strand D, Mariani SM, Stremmel W, Krammer PH, Galle PR (1996) Lymphocyte apoptosis induced by CD95 (APO-1/Fas) ligand-expressing tumor cells a mechanism of immune evasion? Nature Med. 2: 1361-1366

99. O'Connell J, Bennett MW, O'Sullivan GC, Collins JK and Shanahan F (1999) The Fas counterattack: cancer as a site of immune privilege. Immunol. Today 20: $46-52$

100. Shimizu M, Fontana A, Takeda Y, Yagita H, Yoshimoto T and Matsuzawa A (1999) Induction of antitumor immunity with Fas/APO-1 ligand (CD95L)transfected neuroblastoma neuro-2a cells. J. Immunol. 162: 7350-7357

101. Seino K, Kayagaki N, Takeda K, Fukao K, Okumura K and Yagita H (1997) Contribution of Fas ligand to $\mathrm{T}$ cell-mediated hepatic injury in mice. Gastroenterology 113: 1315-1322

102. Arai H, Gordon D, Nabel EG and Nabel GJ (1997) Gene transfer of Fas ligand induces tumor regression in vivo. Proc. Natl. Acad. Sci. USA 94: 13862-13867 